\title{
10 \\ LIVING WITH MOUNT LAMINGTON IN POSTCOLONIAL TIMES
}

\section{New Histories}

The Orokaiva have had a remarkable history since white men first landed on their shores in 1874 asserting their authority and firing their guns. They faced the imposition of colonial control; the invasion of gold miners; deadly battles with white men; the establishment of a new religion, Christianity, in its Anglican form; the banning of cultural behaviours such as cannibalism and inter-tribal fighting; racial discrimination; appropriation of traditional lands for colonial purposes; learning to understand, speak and write the foreign language of English; a deadly world war in which Orokaiva men played an enforced role mainly as carriers of supplies and wounded Allied and Japanese soldiers; public hangings for betraying missionaries and others to occupying Japanese forces; and, finally, the return to Higaturu of Australian colonial rule after the war. Their adaptability to new, unstoppable, historical forces and to volcanic disaster stands out.

Australian colonialism continued for almost 25 years after the 1951 eruption at Mount Lamington and a considerable amount of attention was paid during this time to the nature of the volcano and to the economic development and safety of the people living on and near the mountain. Further, this attention carried momentum, meaning there was no decline after 1975 when Papua New Guinea became an independent country. 
That year was also when primary responsibility for managing disasterrisk reduction strategies on Mount Lamington was inherited by the new sovereign nation-state.

New histories are being created today, both nationally and more locally in what is referred to widely and informally as Oro Province, the former 'Northern Division' of colonial times. Further, international volcanology has progressed steadily, providing information and ideas of value in assessing the nature of explosive volcanoes in general, and of Lamington volcano and its eruption of 1951. National and foreign socioeconomic researchers, disaster managers, anthropologists and historians also continue to maintain an interest in the Orokaiva and their volcanic country. An indication of this ongoing work is provided in Appendix B where a post-1975 time sequence of selected events and activities is provided. Four disaster management themes can be discussed in relation to this time series.

\section{Forecasting the Next Eruption}

When will the next eruption take place at Lamington volcano? Will it be any different from the catastrophic one that devastated the lives of the mountain Orokaiva in January 1951? How often do similarly large eruptions break out on the mountain?

The 1951 eruption at Mount Lamington was not necessarily the same as those that have happened in the more distant past or those that may take place in the future at the volcano. The 1951 eruption has been given a Volcanic Explosivity Index of 4 on a VEI scale of $0-8$, and hopefully the next eruption will score less than 4 (Siebert, Simkin and Kimberley 2010; see 2010 in Appendix B). It could be larger, however, as anticipated in the volcanic-hazard maps produced by the Rabaul Volcanological Observatory (RVO) (de Saint Ours 1988). Three hazard zones for pyroclastic flows, mud flows and lava flows are identified by this mapping. The highest hazard area is a 5-kilometre-wide circular area around the summit. A second zone of potential 'flowage' threat consists of numerous radial ribbons extending down the river valleys and having considerable impact to the north, well away from the summit of the volcano. The third zone of potential threat is for widespread pyroclastic flows ranging 8-20 kilometres from the summit crater. These last two hazard zones are notable because they are larger than the devastated areas 
produced by the 1951 eruption, including in the Ambogo River valley. The two proposed zones also cut the Kokoda-Popondetta road in several places, and they reach Popondetta township itself. This is at variance with Dr Fisher's conclusion in 1951 that Popondetta was 'safe for all time' and, therefore, suitable for a divisional headquarters (Murray Administrator $1951 \mathrm{i}, 1)$. Thousands of people today live within the boundaries of the 8-20-kilometre pyroclastic flow zone proposed by de Saint Ours.

Mount Lamington is the kind of volcano that does not produce eruptions very often, at least in comparison to other volcanoes in Papua New Guinea such as Manam and Bagana. Its actual 'eruption periodicity' through time, however, is unknown because the record of historical eruptions is far too short and its longer eruption history is still poorly known. This means that forecasting the start time and duration of the next eruption is very uncertain indeed. The 1951 eruption and its volcanic deposits have received significant attention from investigating scientists in the field, but the best known source for the volcano's early geology is still the published work of Bryan Ruxton undertaken in the 1960s. Ruxton, however, was the first to emphasise the limitations of his fieldwork. His five principal conclusions still remain the basis for any further fieldwork on Lamington volcano (Ruxton 1966a). These conclusions included the fact that Mount Lamington may have been inactive for well over 1,000 years before the 1951 eruption; that the age of Mount Lamington as a whole is probably within the range of $80-100,000$ years; and that explosive activity may have changed during evolution of the volcano as the result of a decrease in the proportion of eruptions producing ash fall deposits, together with a complementary increase in those producing pyroclastic flows.

Ruxton also concluded that each of three weathered 'depositional units' in the upper-ash cover of Mount Lamington probably had durations of about $4-5,500$ years, separated by about 1,000 years of inactivity. How many separate eruptions are present in each of these units is unclear, but the 1,000-year timescales and intervals are roughly consistent with some global statistical data for volcanoes like Lamington that have produced VEI-4 eruptions. The intervals between 376 worldwide eruptions of VEI- 4 magnitude at different volcanoes are mainly in the range 10 to 1,000 years, and the range 100 to 1,000 years has the highest percentage of eruptions of all five different interval categories (Siebert, Simkin and Kimberley 2010). 
Fieldwork is not easy in the Mount Lamington area. Tropical vegetation covers most of the volcano and surrounding terrain, and access is poor or not possible in many parts of the area. Further, rocks and deposits are not well exposed in situ because the volcano is not deeply cut by erosion, except perhaps on the southern flank of the mountain. Deposits produced by the more distant fallout of ash from earlier eruptions are certainly present away from the volcano. However, as the Owen Stanley Range is extremely rugged, sequences may be incomplete because of erosion and any pyroclastic flow history is unlikely to be represented there. Nevertheless, research on the distal ash fall history is worth pursuing if resources could be found for a comprehensive field study even if this requires local drilling and helicopter support. An attempt to map ash layers near or alongside the maintained Kokoda Track is one possibility, given that recent geological work at pits dug for archaeological purposes at Myola Lakes revealed 2.5-metre layers of ash from Mount Lamington together with soil horizons (Davies 2017-18). The age at the bottom of the pits is about 35,000 years but the base of the sequence was not reached by the drilling. The area west of Mount Lamington is rather important in deducing the history and eruptive periodicity of the volcano as high-rising eruption clouds are likely to have deposited ash there at any time of the year because of the year-round high altitude east to west winds, unlike on the eastern side of the volcano (Figure 9.3).

A further aspect of the nature of the volcano that requires attention is research on the gravitational instability of Mount Lamington, bearing in mind the asymmetry of the volcano, the avalanche-amphitheatre shape of the 1951 crater, the presence of debris-avalanche deposits, and ongoing uplift and seismicity in the nearby Owen Stanley Range. Gravitational instability and downslope slippage along a sloping basement were measured recently on Etna volcano in Italy by means of a detailed geodetic survey (Murray et al. 2018). This survey, however, required deployment of numerous GPS receivers operating over an extended period-a field survey that would be expensive and difficult to undertake at Mount Lamington at the present time. 


\section{Instrumental Monitoring by the Rabaul Volcanological Observatory}

The RVO continues its work as the national volcanological service in Papua New Guinea, much as it did in colonial times. Its broad aim and operational style are based on those of observatories that were built in Europe, and especially in Italy on Etna and Vesuvius, in the late nineteenth century and were introduced to the Territory of New Guinea from the Netherlands Indies after the 1937 eruptions at Rabaul.

The observatory's aim in the twenty-first century is defined in the first part of its mission statement: 'to study and monitor volcanoes in Papua New Guinea effectively so that early warnings of volcanic eruptions can be provided to authorities'. This is an aspirational statement that can be applied to most volcanological observatories worldwide. Well-equipped observatories in developed countries such as Japan, the US, Italy and Russia are in a strong position to provide an effective eruption early warning service, particularly on volcanoes where recent eruptions have been monitored and eruption precursors are known. Rabaul volcano is the best monitored volcano in Papua New Guinea, having received extra international development assistance resources in 1983-85 during an earthquake and ground-uplift crisis, and then after the disastrous eruptions of 1994.

The RVO and Papua New Guinea Government are generally limited by available resources in their selection of which, and how many, volcanoes can be monitored instrumentally at any one time. There have been attempts to rank and prioritise those volcanoes that carry what is thought to be the greatest risk, but the choice is difficult and omitting particular volcanoes can be shown, retrospectively, to have been risky when they break out in eruptive activity 'unannounced', as it were. There has been remarkable progress, however, in monitoring the state of terrestrial volcanoes from space using instruments carried on both orbital and geostationary satellites and the results being distributed globally through the internet. For example, the extent and volume of emissions of volcanic sulphur dioxide and water vapour from individual volcanoes can be mapped remotely by satellite. Further, the strides made in satellite-based geodetic monitoring have been outstanding. Detailed digital elevation models of changes for the whole of the surface of a volcano can be mapped by, for example, radar 
methods, and digital elevation model maps produced (see, for example, Wadge et al. 2018). Satellite monitoring of Lamington is likely to be an important methodology during any forthcoming volcanic crisis on the mountain (Figure 10.1).

Mount Lamington is only one of many active or otherwise youthful and, therefore, potentially active volcanoes in Papua New Guinea that could break out in eruption again causing loss of life and property. It is also one of several volcanoes where an attempt is being made by RVO to provide onsite instrumental monitoring to identify early warning signs of future eruptive activity. This investment, however, is costly and is not always sustainable. Volcano-monitoring equipment can deteriorate in the tropical climate, and it can be destroyed or damaged by lightning strikes, theft and vandalism. Further, single instruments such as those installed on Lamington are limited in what they can measure. A single seismometer on the volcano is useful but, ideally, a network of stations is required so that the place of origin of the earthquake can be calculated through triangulation, and any spatial and temporal trends of earthquake epicentres and depths calculated. Similarly, the overall geodetic pattern of ground-level changes on the volcano is best deduced by a network of instruments. Networks, however, are expensive to install and to maintain, especially where access to widely spaced stations is difficult, such as at Lamington.

The RVO headquarters are 675 kilometres from Lamington in a direct line across the Solomon Sea. This means that air travel costs from Rabaul via Port Moresby are expensive for professional volcanological support, on-sight inspection of the volcano, technical repairs, equipment transport and any additional helicopter requirements. Yet, the presence of a local 'volcano observer' at Popondetta equipped with high-frequency radio communications linked to RVO headquarters is advantageous, particularly if the observer responds well to training, stays in the position, gains experience, and secures the confidence of local people and the provincial authorities. The task of 'observing' a volcano such as Lamington that has had no eruptions in recent times can be unrewarding in some ways, yet stressful if the observer becomes the first point of contact when unsubstantiated rumours spread that the volcano is becoming active again and immediate professional advice is needed. 


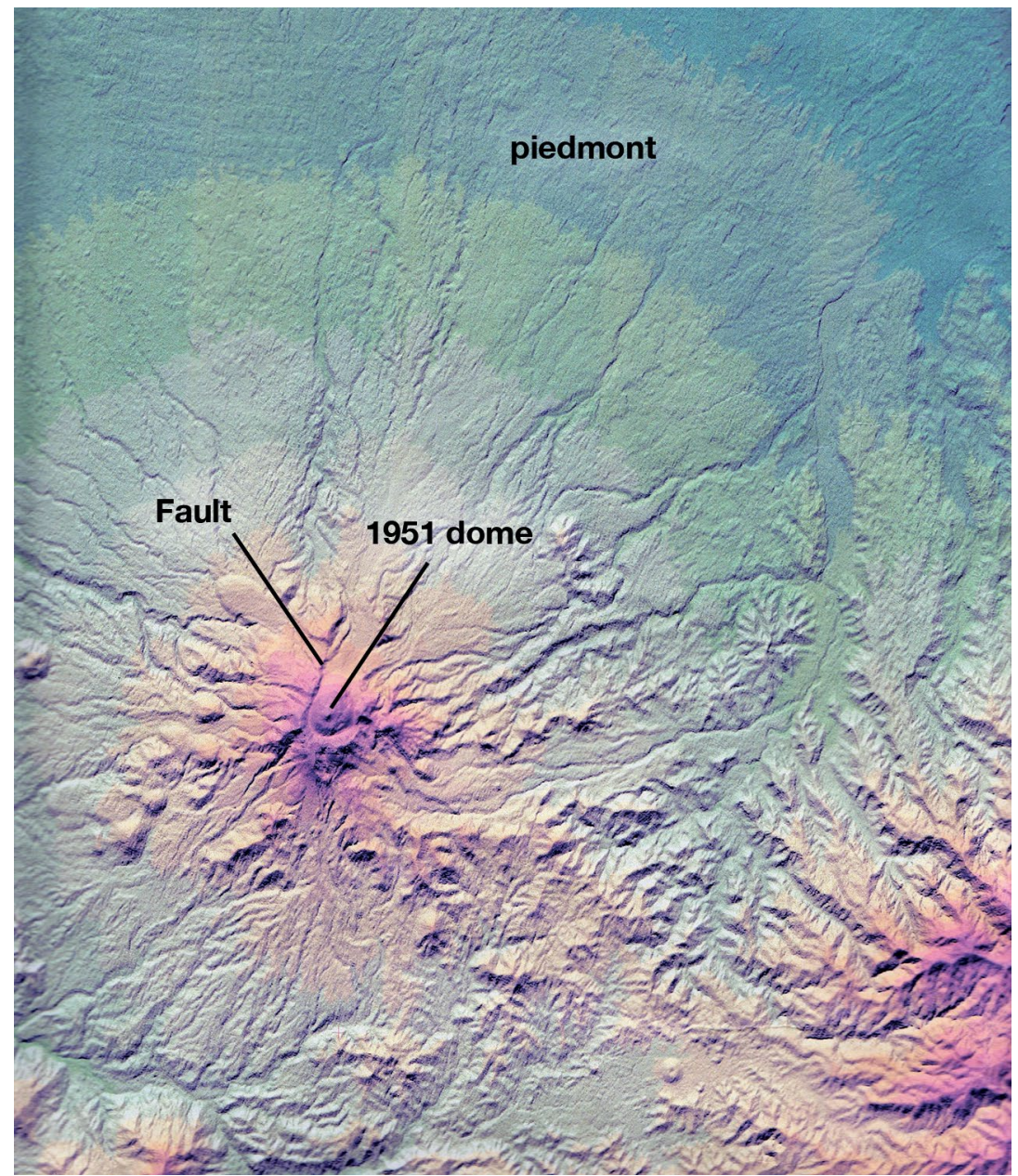

Figure 10.1. Digital elevation model for the Mount Lamington area

This is an example of a satellite-derived digital elevation model image of Mount Lamington today. It was produced by Dorothy D. Pion of the Papua New Guinea Mineral Resources Authority (MRA), Port Moresby, and was provided courtesy of the MRA and H.L. Davies (formerly of the University of Papua New Guinea). North is to the top and the distance across is about 18 kilometres. Note the clustering of lava domes and coulées on and around the mountain; an apparent linear fault running north-north-east on the western side of the 1951 summit dome, defining the north-western edge of the 'avalanche valley'; and the great expanse of the 'piedmont' area to the north towards the Solomon Sea (compare with Figures 9.1 and 9.2). The western end of the Hydrographers Range is seen in the bottom right-hand corner. 
Lamington volcano has not been in eruption since 1951. This represents 69 years of subsequent volcanic inactivity, and the 1951 event being the only eruption in the last, say, 130 years since the mountain was recognised and named during William McGregor's colonial rule. Is instrumental monitoring worthwhile in the short term at Lamington in a situation in which intervals between eruptions may be measured in centuries or even millennia? This question is relevant especially in a situation in which other unmonitored volcanoes in Papua New Guinea may have a greater need at any particular time. A recent example is Kadovar Island, an instrumentally unmonitored volcano off the north-east coast of mainland New Guinea, whose previous eruptive activity may have been as long ago as 1,700 $\mathrm{AD}$, but that broke out in eruption in January 2018 causing evacuation of the islanders to displaced persons camps (Global Volcanism Program 2018). Further, there is no instrumental monitoring on the near-neighbour of Lamington, the historically active volcano of Mount Victory, where there is a risk to local communities not only of future explosive eruptions but also possible collapse of the coastal cone and the generation of tsunamis that could have widespread effects along coastlines of the Solomon Sea.

\section{Commemoration and Communication}

Mount Lamington today is shrouded in green, as it was before the 1951 eruption. The colonial disaster can be recalled by only a very few survivors and eyewitnesses of the disaster who still live in Oro Province or in Australia, most of whom were children at the time of the eruption. However, the disaster has not been forgotten. Commemorating the tragedy has been a near constant feature of the 69 years since the catastrophe. Commemorations have been held in both Papua New Guinea and Australia, and commemorative articles have been published in newspapers and magazines, as well as in memoirs, completed at different times since 1951. Grief is still remembered and expressed, including at commemorations of 'Eruption Day' in Oro Province itself. These are, at times, attended by Australians who lost family members in the disaster. Retelling the myth about Sumbiripa and his wife Suja is another effective way of recalling the nature of the mountain and its potential danger.

Remembrance is a key part of the disaster management spectrum. Indeed, 'remembrance' should, perhaps, be regarded as a third ' $r$ ' to be added to the post-disaster phases of relief and recovery. How a disaster is remembered and revisited-either in speech, using the written word, or 
on film and video-is crucial to making a 'lessons learnt' link back to the two pre-disaster phases of prevention and preparedness. A community not forgetting, but rather learning from, disaster experience is a highly effective way of helping to reduce contemporary natural hazard risk, so that communities become more risk-resilient and self-reliant. The second part of the RVO's mission statement, therefore, is: 'To work in partnership with ... authorities and ... communities to promote awareness of volcanic hazards and risks so that the communities become self-reliant'. The RVO is a source of information about the nature of volcanoes, particularly those in Papua New Guinea, and this knowledge can be put to good use in community awareness-raising work organised in partnership with local communities, their schools and colleges, local and provincial government authorities, and national disaster management agencies.

Historical memory and disaster memorialisation also have potential economic advantages, as evidenced by the numerous war tourists who travel to commemorations at war cemeteries, memorials and battlefields throughout the world. This is a phenomenon referred to by some people as 'dark tourism' (e.g. Lennon and Foley 2000), but by others as exemplifying the economic use of history as a 'resource' (Stead 2018). The Kokoda Track is one such war-linked attraction in Papua New Guinea. Higaturu could attract tourism because of the volcanic destruction of the Australian government station there in 1951 and also because of the systematic and horrific hangings of Orokaiva by the Australian Army in 1943. It is, therefore, a potential destination for guided tours and trekkers travelling along the Kokoda Track. Construction of a new memorial, together with a museum and guesthouse, was proposed and promoted several years ago by Hohorita people (Saunders 2018-19). Forgetting past tragedies- that is, the Higaturu hangings and the 1951 volcanic disaster-is unlikely to take place soon in these circumstances. The Mount Lamington Memorial Cemetery in Popondetta is a colonial park that equally could attract foreign tourists on account of its troubled history, even if does not meet the full requirements of people in modern-day Oro Province in remembering properly the thousands of Orokaiva killed, and particularly those at Hohorita who are the descendants of the Sangara.

Contemporary remembering of the Mount Lamington disaster is ambivalent and ambiguous in its content and expression (Stead 2018). People today speak bitterly about the failure of the colonial administration to provide early warning of the eruption and to provide for an evacuation, but there is also a shared experience that connects villagers around Higaturu 
with the descendants of those Europeans who died in the eruption and, thus, a motivation to pursue opportunities that they hope might lead to enduring relationships with them, if not to economic opportunities. An example is the way in which Pamela Virtue and her late father, Cecil Cowley, were honoured by people during the Virtues' visits in 2003 and 2004, including some people saying that District Commissioner Cowley had, in fact, recommended an evacuation (Cowley and Virtue 2015; see also Didymus 1974). Another version of this story, however, includes Mrs Virtue being petitioned by villagers for money to fund the proposed memorial, and asserting that her father was responsible for the high death toll of Orokaiva people in 1951 (Stead 2018).

\section{What is the Risk?}

A community can be said to be 'at-risk' from a natural hazard, such as a volcanic eruption or cyclonic flooding, if the hazard is frequent and if it is likely to have high impact when eventually it does strike. There is no risk if people do not live or work in such hazardous zones, but this means that when they do, the risk is a combination both of 1) the magnitude and frequency of the hazard and 2) what might be lost as a result of the hazard impact. Crucial to risk assessment, then, is knowing something about 'exposure' - that is, the vulnerability of populations, their built environment, services, agricultural lands, road systems, effective means of escape, up-to-date disaster management plans and so forth.

Risk can be mapped and semi-quantified in areas where there is good spatial or mappable information on likely hazard impacts and what might be lost. Such information can be digitised and added to Geographic Information Systems (GIS) where any one point on the digital maps can be linked to databases or 'attribute' data on what is found at that point-how many people, how much investment, proximity and access to essential services and so on-in other words, what is 'at-risk'. GIS are used globally for a wide range of purposes, but the term 'risk-GIS' has been introduced specifically as a means of focusing on how these systems can be used in disaster management for assessing risk and so contribute to plans for disaster prevention and preparedness (e.g. Granger 2000). There is 'nothing more certain in the disaster management business than the fact that once a disaster starts to unfold, it is too late to start looking for the information needed to manage it' (Granger 2000, 20). 
The extent to which such risk-GIS technology can be introduced in Oro Province, maintained, updated and staffed by people trained to use it is resource dependent. This digital approach was introduced in East New Britain Province in 2013 (Bear-Crozier et al. 2013), but its usefulness has yet to be assessed during the real-time situation of a new, developing volcanic disaster.

What then can be said about the volcanic risk at Lamington volcano today? There is little doubt that more is 'at-risk' in the area compared to conditions in 1975 when Australian colonialism ended. The area devastated in 1951 has been reoccupied in part. There are more people, larger villages, more essential services, greater investment, and there is an agricultural economy underpinned by a now well-established oil palm industry. Further, there are many places on and near the mountain where communities escaped and survived the worst of the 1951 disaster, but which today are in areas that potentially are exposed to future volcanic activity and have been mapped as being in the flowage-hazard zones of the volcano. The risk on this basis alone can be said to be increasing even though it has not yet been quantified.

The problem in assessing the risk at Mount Lamington is not so much dealing with the vulnerability or 'exposure' of the communities, but rather with the uncertainties surrounding the volcanic hazard itself. The risk is high in the Mount Lamington area if there is confidence or near certainty that another VEI-4, or higher, explosive eruption will take place over the next few years. Conversely, it is very low if the next major explosive eruption is centuries away, or if the next eruption will be a smaller one limited to, say, the western flank of the volcano like those that formed the numerous minor satellite volcanoes. What should be done in these circumstances?

Communities themselves need to continue maintaining vigilance. Felt earthquakes, bare patches in the summit area, landslides, unusual smells and, of course, 'roars from the mountain', are all potential signs of volcanic unrest at Mount Lamington that can be detected and reported by people living on and near the volcano. Even the unusual behaviour of animals near villages, as featured in The Mountain, a novel about the Omie people and based on actual reports, should not be ignored (Modjeska 2012, 2017). The seismometer, tiltmeter and high-frequency radio system deployed by the RVO are advisable as an adjunct to community observations, provided government resources can be found to continue 
sustaining the instrumentation and assuming that vandalism and theft of the equipment do not take place. However, communities relying primarily on these technologies for early warnings of eruptions - that is, ahead of their own 'frontline' detection of changes-is not as advisable as the communities themselves acting as triggers for rapid-response investigations by RVO staff, even though 'false alarms' can be expected. Self-reliance can be enhanced too by continuing hazard-awareness information visits by RVO staff and other disaster managers. Hazard and risk maps should be updated progressively and displayed in schools and community centres, for example. There is also today the communication power of the internet, mobile telephones and social media-twenty-firstcentury global technology that was barely imaginable in 1951 .

The name 'Higaturu' is now set securely in history. It refers to the stilldeserted place associated with the Australian administration's former Higaturu Government Station where the wartime hangings of Orokaiva took place and which was subsequently destroyed by a catastrophic volcanic eruption. The name intones anger. Thus, the Anglican leader at Popondetta, Reverend Bishop Lindsley Ihove, is reported as saying that the 'human ignorance' of the white colonial authorities 'made people die' (Stead 2018, 25). This can hardly be disputed, the ignorance being equated with a lack of both relevant information and adequate experience of what to expect.

There was no colonial knowledge at Higaturu in January 1951 that Mount Lamington was a potentially active volcano, although there were weak pre-1951 hints that it might be. Further, the indecisive, almost diffident way in which the early warning signs of a catastrophe were dealt with by colonial authorities, and the decision to delay making any announcement to evacuate, turned out to be ill-advised and incorrect. Vulnerability soon turns into disaster when the wrong human decisions are made on the basis of inadequate knowledge. However, the written records left by many people, which form the basis of this book, mean that lessons can be learnt and that future volcanic disasters at Mount Lamington can be mitigated, and even avoided. 
This text is taken from Roars from the Mountain: Colonial Management of the 1951 Volcanic Disaster at Mount Lamington, by R. Wally Johnson, published 2020 by ANU Press, The Australian National University,

Canberra, Australia.

doi.org/10.22459/RM.2020.10 